\title{
Successful repair of Aortic Rupture in a patient with bicuspid aortic valve after Aortic Valve Replacement: a rare case.
}

\author{
Dikshya Joshi', Smriti M. Bajracharya ${ }^{2}$, Rabindra B. Timala', Navin C. Gautam¹, Yogeshwor M. \\ Singh ${ }^{1}$, Apurba Thakur ${ }^{1}$, Jyotindra Sharma ${ }^{1}$
}

${ }^{1}$ Department of cardiac surgery, Shahid Gangalal National Heart Centre, Kathmandu, Nepal.

${ }^{2}$ Department of cardiac anesthesia, Shahid Gangalal National Heart Centre, Kathmandu, Nepal.

Corresponding Author:

Dikshya Joshi

Department of cardiac surgery, Shahid Gangalal National Heart Centre, Kathmandu, Nepal.

Email: drdixajoshi@gmail.com

ORCID ID NO: 0000-0002-1031-325X

Cite this article as: Joshi D, Bajracharya SM, Timala RB, et al. Successful repair of Aortic Rupture in a patient with bicuspid aortic valve after Aortic Valve Replacement; a rare case. Nepalese Heart Journal 2020; Vol 17 (1), 49-51

Submitted date: $28^{\text {th }}$ February 2020

Accepted date: $21^{\text {st }}$ April 2020

\begin{abstract}
The occurrence of acute aortic rupture after aortic valve replacement is unusual; but catastrophic. We report a case of a 71-year-old gentleman with a bicuspid aortic valve who developed acute aortic rupture after an elective bioprosthetic aortic valve replacement surgery in which successful repair was carried out with the preservation of the prosthetic valve.
\end{abstract}

Keywords: acute aortic rupture; bicuspid aortic valve; post aortic valve replacement.

DOI: https://doi.org/10.3126/njh.v17i1.28813

\section{Introduction}

Aortic rupture after aortic valve surgery is a rare and unpredictable complication. If it does occur, it can jeopardize a patient's life immediately. Prevention, early recognition, and immediate appropriate management are crucial in reducing this deleterious complication. It can be treated successfully if it is immediately recognized and adequately managed.

\section{Case Report}

A 71-year-old male was referred to us from the cardiology clinic with a history of dizziness, blackouts and complaints of chest pain on slight exertion, which developed over a course of a few weeks. He had a history of hypothyroidism for which he was taking levothyroxine regularly. He gave no history of hypertension, smoking and contributory family history. Echocardiography revealed a bicuspid aortic valve (BAV) with degenerative severe aortic stenosis with peak pressure gradient across the aortic valve being $121 \mathrm{mmHg}$. The ascending aorta was $32 \mathrm{~mm}$ in width. Under the clinical impression of severe aortic stenosis, the patient was planned for an early aortic valve replacement with a bioprosthesis.
During surgery, the calcified bicuspid aortic valve was noted, which was replaced by a bioprosthesis Perimount valve number 19; the cardiopulmonary bypass (CPB) time was 101 minutes. The patient had BAV and the aortic walls of the patient, especially sinotubular junction, sinus portion and the supra-annular portion were stiff at the initial operation. Nevertheless, the surgery went well without intraoperative complications.

The patient was transferred to the intensive care unit (ICU) with the blood pressure of $110 / 70 \mathrm{mmHg}$, heart rate of $80 \mathrm{bpm}$, on the support of dopamine $3 \mathrm{mcg} / \mathrm{kg} / \mathrm{min}$ and noradrenaline $0.02 \mathrm{mcg} / \mathrm{kg} /$ $\mathrm{min}$. The blood pressure in the perioperative period did not exceed $120 / 80 \mathrm{mmHg}$. However, there was subtle and continuous bleeding throughout the first 10 hours postoperatively, leading to total bleeding exceeding $900 \mathrm{ml}$. Hence, we decided to take the patient for surgical reexploration. About $500 \mathrm{ml}$ of fresh clot was removed from the mediastinum, with few bleeding sites at the sternal wires, and there seemed to be no other bleeding points. Entire suture lines and surface bleeding were thoroughly examined. Hemostasis was secured and the patient was transferred back to the ICU.

At ICU, the blood pressure was again maintained about 110/80 mmHg. There was no further issue of bleeding. Six hours

(a) Nepalese Heart Journal. Nepalese Heart Journal retain copyright and works is simultaneously licensed under Creative Commons Attribution License CC - By 4.0 that allows others to share the work with an acknowledge of the work's authorship and initial publication in this journal

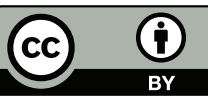


after returning to ICU and meeting all criteria, he was placed on spontaneous ventilation mode aiming for extubation. After 10 minutes, he developed a focal seizure lasting around 25-30 seconds. His blood pressure rose to $150 / 90 \mathrm{mmHg}$. Sudden massive bleeding of 2 liters was noticed in the drain bottle. The patient collapsed and went into asystole. Cardiopulmonary resuscitation was promptly begun and the decision to open the chest immediately was taken. On opening the chest, the mediastinal cavity was completely filled with blood, obscuring the source of bleeding. After suctioning about a liter of blood, the bleeding site was detected at the right side of the aortic free wall approximately $2 \mathrm{~cm}$ distal to the sinotubular junction. Digital compression of the bleeding was done, and the patient was transfused with four pints of red blood cells while resuming open cardiac massage for more than 30 minutes. A partial clamp was used to clamp the torn part of the patient until the patient was stabilized. Few attempts to secure hemostasis were made using felt strips; meanwhile we prepared to transfer the patient to the operation room for further intervention. At the operation theatre, several measures were undertaken for securing hemostasis. The groin was prepared for femoral cannulation if needed and CPB was aided for backup. Several attempts to control the bleeding were made with the help of felt strips and partial clamps. In the meantime, the patient was also being corrected for severe metabolic acidosis. He was transfused with 5.5 liters of crystalloid, 8 units of packed red blood cells, six pints of fresh frozen plasma, and two pints platelet. However, the reconstitution of the aorta with interposition of a synthetic graft may have been necessary, had the bleeding not been controlled with the initial repair. The total time of the resuscitation was around 7 hours in the operation room. The patient was transferred back to the ICU, metabolic acidosis was corrected with sodium bicarbonate infusion and warming the patient with the help of a forced-air warming device, and the patient was sedated for 48 hours. The patient responded nicely and was extubated on the third postoperative day. His rest of the postoperative course was uneventful and he had a good recovery. $\mathrm{He}$ was discharged on the twelfth postoperative day.

\section{Discussion}

Aortic rupture after aortic valve replacement is an uncommon scenario, but a serious complication. Such scenarios, if left unrecognized, have high mortality. Prompt recognition is of paramount importance. This case demonstrates an uncommon presentation of aortic rupture after aortic valve replacement in a patient with BAV. BAV disease is the most common congenital cardiac defect with a prevalence of approximately $1 \%{ }^{1}$ Irrespective of the functional state of the valve, $75 \%$ of the patients with BAV demonstrate grade 3 degenerative changes in the ascending aorta due to increased metalloproteinase activity and apoptosis of the smooth muscle cells in the media ${ }^{2}$ processes that reduce the tensile strength of the aortic wall. On the basis of published reports, BAV should be considered a disease of the entire aortic root and is associated with increased aortic stiffness. ${ }^{1,3}$

Since the aortotomy was completely repaired using double layer 4-0 prolene without bleeding, we did not perform any procedures on the aortic root. Although we cannot be sure of the cause of the rupture of the aortic root in our context, because the histopathological specimen was not sent, an aortic tear was most likely in this patient due to reduced elastic properties of the proximal aorta triggered by seizure and temporary rise in blood pressure. Since the aorta is already compromised, such an acute increase in blood pressure rise may be sufficient to rupture the aorta.

In this case, or in any other cases involving BAV, there seems to be a severe alteration of the aortic wall, which is potentially capable of evolving into acute aortic pathology, so it becomes absolutely necessary to meticulously implant the valve paying special attention to the tissues around the aortic wall. Detailed examination of the aorta, including the incision site and the surface around before closure, is mandatory. In some instances, when the thinned aorta becomes difficult to be repaired with just conventional closure techniques, additional management including root replacements might be necessary.

In our case, the bleeding site was detected at the right side of the aortic free wall approximately $2 \mathrm{~cm}$ distal to the sinotubular junction. The high velocity, turbulent jet propagates to the greater curvature of the tubular ascending aorta leading to its subsequent wall thinning and enlargement. ${ }^{4}$ Frequently associated finding is dilation of the proximal ascending aorta. The prevalence of aortic root dilatation was 53\% in BAV patients. ${ }^{5}$ However, in our case, there was no dilated aorta and aortic root.

Aggressive oversizing ( $\geq 20 \%)$ of bioprosthetic valves, a discrepancy between the size of the native annulus and the prosthesis, is thought to carry an increased risk for annular rupture. ${ }^{6}$ However, it should be emphasized that overdistension of a healthy aortic annulus is a completely different process compared to degenerative aortic valve stenosis with the ubiquitous presence of calcification. ${ }^{6,7}$ Since our patient had a very fragile aortic wall, even though he had an aortic annulus of $21 \mathrm{~mm}$ measured preoperatively, the $19 \mathrm{~mm}$ Perimount valve was implanted to minimize the complication due to oversizing.

In acute situations, immediate suspicion of possible aortic rupture is crucial. The primary therapeutic goal is to maintain or restore hemodynamic stability to secure adequate coronary and cerebral perfusion. The principal rule is that any acute massive arterial bleeding in the pericardium with no identifiable cause should be considered as suspected aortic rupture. Importantly, the initial symptoms may be mild or unclear, with stable hemodynamics that quickly deteriorates as the dynamic process of rupture continues. In hemodynamically stable patients, the correct diagnosis is established by echocardiography, aortography, and/or coronary angiography, however, in unstable patients, direct exploration through a median sternotomy is indicated. ${ }^{8}$ Treatment approaches include an immediate surgical intervention to identify and repair the rupture site with or without ascending aortic replacement without delay with or without the immediate institution of CPB. . $^{6,7,8}$

Surgical strategy and the type of surgical treatment depend on the type of aortic rupture. Initial treatment should be aimed at controlling pain and the hemodynamic state followed by considering the necessity and indications for surgical treatment by repairing the lesion with or without replacing the diseased aortic segment with an artificial graft. ${ }^{8}$ Maintaining the hemodynamic condition of patients with free aortic rupture is difficult. The majority of patients with aortic rupture and continuous bleeding will not survive even with massive transfusion and large doses of catecholamine. ${ }^{8}$ In our case, we repaired the tear with felt strips and partial clamp. However, the reconstitution of the aorta with interposition of a synthetic graft, or aortic root replacements might have been necessary at different times. Regardless of the lesion, BAV always guarantees extra meticulous surgical effort to strengthen the aortic wall. Surgeon's expertise and each individual patient's case determine the ultimate management decision as occurred in our case. The current knowledge is limited in the literature regarding the incidence of acute aortic rupture after aortic valve replacement and factors associated with its development. In conclusion, we report a case of aortic rupture after aortic valve replacement. This rare complication may rapidly lead to lifethreatening consequences including death without prompt recognition and immediate intervention. 


\section{References}

1. Siu S.C., Silversides C.K., et.al. Bicuspid aortic valve disease. J Am Coll Cardiol 2010;55:2789-2800. https://doi. org/10.1016/j.jacc.2009.12.068. PMid:20579534

2. Braverman AC1, Güven H, Beardslee MA, et.al. The bicuspid aortic valve. Curr Probl Cardiol. 2005, (9):470-522. https:// doi.org/10.1016/j.cpcardiol.2005.06.002. PMid:16129122

3. Nistri S., Sorbo M.D., Basso C., et.al. Bicuspid aortic valve: abnormal aortic elastic properties. J Heart Valve Dis 2002;11:369-374

4. Girdauskas E, Borger MA. Bicuspid aortic valve and associated aortopathy: an up-date. Seminars in Thoracic and Cardiovascular Surgery, January 2013. https://doi. org/10.1053/j.semtcvs.2014.01.004. PMid:24673960

5. Biner S., Rafique A.M., Ray I., et.al. Aortopathy is prevalent in relatives of bicuspid aortic valve patients. J Am Coll Cardiol 2009;53:2288-2295, https://doi.org/10.1016/j. jacc.2009.03.027. PMid:19520254. PMCid:PMC2761956

6. Pasic M, Unbehaun A, Buz S, et al. Annular Rupture during Transcatheter Aortic Valve Replacement: Classification, Pathophysiology, Diagnostics, Treatment Approaches, and Prevention. JACC: Cardiovascular Interventions; 2015; 8 (1A): 1-9. https://doi.org/10.1016/j.jcin.2014.07.020 PMid:25616813

7. A. Eker, F.B. Sozzi, F. Civala, et.al. Aortic annular rupture during transcatheter aortic valve implantation: safe aortic root replacement Eur J Cardiothorac Surg, 2012; 41:1205. https:// doi.org/10.1093/ejcts/ezr146. PMid:22250069

8. Fukui T. Management of acute aortic dissection and thoracic aortic rupture, J Intensive Care. 2018; 6: 15. https:// doi.org/10.1186/s40560-018-0287-7. PMid:29507729 PMCid:PMC5831732 